\title{
Short-Term Didactic Lecture Course and Neurosurgical Knowledge of Emergency Medicine Residents
}

\author{
Mehdi Zeinalizadeh ${ }^{1,2,}$; Keyvan Tayebi Meybodi ${ }^{1}$; Farid Maleki ${ }^{1}$; Meysam Mohseni ${ }^{1}$; Seyed \\ Mojtaba Miri ${ }^{1}$; Farideh Nejat ${ }^{3}$; Mohammad Taghi Talebian ${ }^{4}$; Hooman Hossein Nejad ${ }^{4}$; \\ Zeinab Mohajer ${ }^{4}$ \\ ${ }_{2}^{1}$ Department of Neurosurgery, Imam Khomeini Hospital, Tehran University of Medical Sciences, Tehran, IR Iran \\ ${ }_{3}^{2}$ Brain and Spinal Cord Injuries Repair Research Center (BASIR), Imam Khomeini Hospital, Tehran University of Medical Sciences, Tehran, IR Iran \\ ${ }^{3}$ Department of Neurosurgery, Children's Hospital Medical Center, Tehran University of Medical Sciences, Tehran, IR Iran \\ ${ }^{4}$ Department of Emergency Medicine, Imam Khomeini Hospital, Tehran University of Medical Sciences, Tehran, IR Iran \\ ${ }^{*}$ Corresponding author: Mehdi Zeinalizadeh, Department of Neurosurgery, Imam Khomeini Hospital, Tehran University of Medical Sciences, Tehran, IR Iran. Tel: +98-2166591320, \\ E-mail: mzeinalizadeh@tums.ac.ir
}

Received: January 23, 2015; Accepted: January 25, 2015

Background: Neurological emergencies are common causes of emergency department visits. The need for emergency medicine (EM) physicians and/or specialists worldwide is growing to meet this requirement. Delivery of time-sensitive interventions and lifesaving care requires training.

Objectives: The aim of this study was to evaluate the level of knowledge of EM residents in neurosurgical emergencies before and after holding an education course.

Materials and Methods: In this cross-sectional study, 28 EM residents during their first and second years of training were evaluated. A multiple choice questionnaire containing 60 questions about neurosurgical emergencies (radiology, cranial, spinal and spinal cord, and pediatrics) was designed by 3 neurosurgeons. Without any prior notification, pre-training exam was taken. A short-term course of education via didactic lectures in 8 sessions was held after the first exam. At the end of the course, participants were tested again in the similar conditions as the pre-training test. Scores were analyzed using paired t-tests.

Results: Performance of residents was significantly improved from pre-training test with mean scores from 35.7 to 42.03 on post-training test $(\mathrm{P}<0.001)$. Scores between males and females in the two exams were not significantly different $(\mathrm{P}=0.063)$. The second-year residents had a significantly better performance compared to the one-year residents $(\mathrm{P}<0.001)$.

Conclusions: At present, there is no standard education program that provides the optimum needs for EM residency training. To deal with the need of improving EM residency education in neurosurgical emergencies, teaching by neurosurgeons either through formal lectures and clinical rotations or other similar educational methods could be advantageous.

Keywords: Emergency Medicine; Didactic Lecture; Internship and Residency

\section{Background}

Neurosurgical emergencies such as traumatic craniospinal injuries, and spontaneous subarachnoid and intracerebral hemorrhages pose a critical public health and socioeconomic problem throughout the world (1, 2). Neurological complaints such as headache or stroke are frequent causes of emergency department visits. The morbidity and mortality of such injuries if left undiagnosed can be extensive (3). In some countries, emergency medicine (EM) specialists are the first care givers of such patients. Thus, residents being trained in EM need appropriate skills in evaluation, diagnosis, and treatment of neurosurgical emergencies to provide the best available patient care (4). Lack of sufficient knowledge and experience in this area may lead to suboptimal patients' outcome and high morbidity or even mortality. For this purpose, EM residency programs should ensure adequate training in such life-threatening emergencies.
In our country, the first EM residency program was introduced in 2001 in two medical schools. At present, our national curriculum of EM residency education lacks didactic programs in neurosurgical emergencies and rotations in neurosurgical departments. So, we hypothesized that our EM residency training programs do not currently provide adequate training in this realm. Despite numerous new methods for training, lectures are routinely used methods worldwide and we also adhered to this principle to judge its outcome on EM residency training in catering for neurosurgical emergencies.

\section{Objectives}

The aim of the study was to evaluate the level of knowledge of emergency medicine residents in neurosurgical emergencies before and after holding an education course.

Copyright (C) 2015, Tehran University of Medical Sciences. This is an open-access article distributed under the terms of the Creative Commons Attribution-NonCommercial 4.0 International License (http://creativecommons.org/licenses/by-nc/4.0/) which permits copy and redistribute the material just in noncommercial usages, provided the original work is properly cited. 


\section{Materials and Methods}

\subsection{Study Design and Population}

This cross-sectional study was conducted on 36 EM residents in their first and second year of training between March and June 2012. Their 3rd years of training were excluded because they were serving governmental mission in EM departments in other cities.

Residents participated without prior notification in pre-training test including 60 multiple choice questions about various practical subjects in neurosurgical emergencies (radiology, cranial, spinal and spinal cord, and pediatric emergencies) (Table 1). The questionnaire was designed by three expert neurosurgeons and was subsequently revised by two EM specialists (Mohammad Taghi Talebian and Hooman Hossein Nejad). After that, a shortterm course of didactic lectures by an expert neurosurgeon, totally for 16 hours and during 8 weeks, was held. The lectures included slides about neurosurgical emergencies in various forms such as images, problem based cases, and videos to manage EM department patients. Lectures covered the whole of the questions. Immediately at the end of this course, EM residents participated in post-training test by a questionnaire with similar concepts, again without any prior notification. They were neither aware of the second exam nor were provided the questions or their answers after the first one. Finally, answers to both pre- and post-training tests were evaluated with each correct answer as one point. Eight EM residents were excluded because of failing to take part in both the tests. Some of those excluded subjects were on duty shifts at the mentioned hospitals in the emergency de- partment. Included subjects were present in more than $80 \%$ of the lectures. The study was approved by the institutional medical research ethics committee.

\subsection{Statistical Analysis}

Comparison of scores obtained in pre- and post-training tests was performed using paired t-tests. All statistical analyses were done by SPSS version 18 (SPSS Inc. Chicago). $\mathrm{P}$ value less than 0.05 was considered statistically significant.

\section{Results}

Scores, before and after training courses are being summarized (Table 2). Eighteen residents (64.3\%) were male and 10 (33.7\%) female. The number of residents in 1 st and 2nd years was the same (14 residents). The minimum and maximum obtained scores in pre-training test were 26 and 45 , respectively with mean of $35.07 \pm 4.29$. Post-training sores showed a significant increase (minimum = 33; maximum $=48 ;$ mean $=42.03 \pm 4.39 ; \mathrm{P}<0.001)$.

Table 1. Number of Multiple Choice Questions Based on Various Items in Neurosurgical Emergencies

\begin{tabular}{lc}
\hline Neurosurgical Emergency Item & Number of MCQs ${ }^{\text {a }}$ \\
\hline Cranial and cerebral & 28 \\
Spinal and spinal cord & 15 \\
Pediatrics & 7 \\
Radiology & 10 \\
Total & 60 \\
\hline
\end{tabular}

a Abbreviation: MCQ, multiple choice question.

Table 2. Pre-training and Post-training Achieved Scores ${ }^{a}$

\begin{tabular}{|c|c|c|c|c|}
\hline \multirow[t]{2}{*}{ Item } & \multirow[t]{2}{*}{ Maximum Achievable Score } & \multicolumn{3}{|c|}{ Achieved Score } \\
\hline & & Min & Max & Mean \pm SD \\
\hline Total pre-test & 60 & 26 & 45 & $35.07 \pm 4.29$ \\
\hline Total post-test & 60 & 33 & 48 & $42.03 \pm 4.39$ \\
\hline Cranial and cerebral & 28 & & & \\
\hline Pre-test & & 10 & 19 & $16.17 \pm 2.09$ \\
\hline Post-test & & 11 & 23 & $18.71 \pm 2.4$ \\
\hline Spinal and spinal cord & 15 & & & \\
\hline Pre-test & & 7 & 12 & $9.6 \pm 1.31$ \\
\hline Post-test & & 7 & 14 & $11.21 \pm 1.7$ \\
\hline Pediatric & 7 & & & \\
\hline Pre-test & & 1 & 7 & $4.71 \pm 1.38$ \\
\hline Post-test & & 4 & 7 & $5.67 \pm 1.09$ \\
\hline Radiology & 10 & & & \\
\hline Pre-test & & 2 & 10 & $4.57 \pm 1.87$ \\
\hline Post-test & & 4 & 9 & $6.42 \pm 1.42$ \\
\hline
\end{tabular}

\footnotetext{
a Abbreviations: Max, maximum; Min, minimum; and SD, standard deviation.
} 
According to specified areas as depicted in Table 2 (radiology, brain, spine and spinal cord, and pediatric neurosurgical emergencies), differences between pre-training and post-training scores were significant $(\mathrm{P}<0.001)$, indicating clearly improved residents' performance after the mentioned education course.

There was no statistically significant difference between males and females in pre-training or post-training scores $(\mathrm{P}>0.05)$. Also, post-training scores among the 2nd year residents were significantly higher $(\mathrm{P}<0.001)$.

\section{Discussion}

Medical education technology shapes and channels medical education policy as research advancements provide new ways to educate and evaluate physicians. Educational technology and policy coalesce with emphasis on effectiveness, efficacy, and trainee and teacher morale as new models of medical teaching and testing are introduced (5).

Nowadays, numerous methods, curricular or extracurricular, such as clinical experience, lectures, reading, laboratory work, problem-based learning (PBL), stimulation-based medical education (SBME), team-based learning (TBL), and many others are applied in medical education (5-10). Despite different new methods for training, lectures are the routinely methods used worldwide.

In our country, EM specialty is a neoteric profession and curricular education is the mainstay of residency training. Emergency medicine specialists are the first-line physicians in diagnosing patients during emergency department visits. To the best of our knowledge, according to the last revised national curriculum for EM residency, approved by ministry of health and medical education in November, 2008, special program or education for tackling neurosurgical emergencies is not included (11). This concern is not a peculiar subject of challenge in our EM residency curriculum, as Stettler et al. (3) showed that only a minority of EM programs in United States of America had structured training in the neurological surgery field or clinical rotations. Moreover, currently the primary method of educating EM residents outside the emergency department is through didactic lectures, supplemented by required reading (5).

Lack of appropriate knowledge about neurosurgical emergencies or having obsolete data and consequently malpractice can contribute to catastrophic consequences. Also, the information available in textbooks typically lags temporally behind that found in most current literature discussed on clinical rotations (3). For example, in the recent months, relevant articles in modern management of traumatic brain and spinal cord injuries have been published and as such are not included in most texts (12-14). Moreover, wide varieties of neurosurgical emergencies along with the pros and cons in this field further highlight the need for strict and up to date education in their diagnosis and management.
Our study revealed that the knowledge of EM residents (1st and 2nd year) in neurosurgical emergencies was below our expectations. Also, it showed that a short-term course of focused education by a neurosurgeon could improve their knowledge and probably performance. With regard to the effectiveness of such educative programs, the role of a neurosurgeon as an instructor for EM residents seems to be warranted.

Based on our results, inclusion of similar plans or rotations in EM residency curriculum and programs during the second year (in comparison to the first year) seems to be more advantageous. Because of the importance of on time care in EM departments especially for neurosurgical patients, we believe this is the area of greatest need for additional and comprehensive researches to specify the best methods of education of EM residents to cope with ubiquitous neurosurgical emergencies.

We have to denote that the goal of this study was neither promotion of this kind of training, nor composition of a new curriculum; but it was to emphasize the absence of a special training course for neurosurgical emergencies (either by a neurosurgeon or an EM specialist).

\subsection{Limitations}

There were several limitations in the current study, including absence of 3rd year residents in the study due to governmental mission, limited number of participants, lack of practical assessment of their neurosurgical knowledge simultaneously, the probable short-term effect of the lectures on the knowledge of residents, gain of knowledge due to other sources during the lecture course is a possibility, although this could be eliminated by the short-term nature of the course.

EM residency training curriculum may not cover extensive and sufficient education in neurosurgical emergencies. The most common method of EM residents' education in this area is through reading and occasional lectures without any rotations in different specialties, especially the neurosurgical specialty. Because of the number and importance of neurosurgical emergencies seen in emergency departments, improvement of skill and knowledge of EM residents is vital. To achieve the optimum, training programs are better to be revised to include teaching by a neurosurgeon or neurosurgery rotations.

\section{Acknowledgements}

We would like to thank all the EM residents in Tehran University of Medical Sciences to participate in our course voluntarily.

\section{Authors' Contributions}

Mehdi Zeinalizadeh and Meysam Mohseni conceived and designed the study. Mehdi Zeinalizadeh, Keyvan Tayebi Meybodi, and Zeinab Mohajer prepared the first draft of the article. Farid Maleki analyzed the data. Seyed 
Mojtaba Miri, Mohammad Taghi Talebian, and Hooman Hossein Nejad prepared the questionnaire. Farideh Nejat reviewed the manuscript draft.

\section{References}

1. Arce D, Sass P, Abul-Khoudoud H. Recognizing spinal cord emergencies. Am Fam Physician. 2001;64(4):631-8.

2. Byrne RW, Bagan BT, Slavin KV, Curry D, Koski TR, Origitano TC. Neurosurgical emergency transfers to academic centers in Cook County: a prospective multicenter study. Neurosurgery. 2008;62(3):709-16.

3. Stettler BA, Jauch EC, Kissela B, Lindsell CJ. Neurologic education in emergency medicine training programs. Acad Emerg Med. 2005;12(9):909-11.

4. Rainer TH. Emergency medicine-the specialty. Hong Kong Med J. 2000;6(3):269-75.

5. McGaghie WC, Issenberg SB, Petrusa ER, Scalese RJ. A critical review of simulation-based medical education research: 2003 2009. Med Educ. 2010;44(1):50-63.

6. Tan NC, Kandiah N, Chan YH, Umapathi T, Lee SH, Tan K. A controlled study of team-based learning for undergraduate clinical neurology education. BMC Med Educ. 2011;11:91.

7. Aggarwal R, Mytton OT, Derbrew M, Hananel D, Heydenburg M, Issenberg B, et al. Training and simulation for patient safety. Qual Saf Health Care. 2010;19 Suppl 2:134-43.
8. Siassakos D, Bristowe K, Draycott TJ, Angouri J, Hambly H, Winter $\mathrm{C}$, et al. Clinical efficiency in a simulated emergency and relationship to team behaviours: a multisite cross-sectional study. BJOG. 2011;118(5):596-607.

9. Chandawarkar RY, Ruscher KA, Krajewski A, Garg M, Pfeiffer C, Singh R, et al. Pretraining and posttraining assessment of residents' performance in the fourth accreditation council for graduate medical education competency: patient communication skills. Arch Surg. 2011;146(8):916-21.

10. Ma IW, Brindle ME, Ronksley PE, Lorenzetti DL, Sauve RS, Ghali WA. Use of simulation-based education to improve outcomes of central venous catheterization: a systematic review and metaanalysis. Acad Med. 2011;86(9):1137-47.

11. Jalili M, Bidari A, Nejati A, Arhami A, Farahmand SH, Zare MA, et al. Curriculum for emergency medicine residency program. Iranian council for graduate medical education.: Ministry of health and medical education;. Available from: http://cgme.behdasht.gov.ir| index.aspx?siteid=264\&pageid $=22758$.

12. Kolias AG, Guilfoyle MR, Helmy A, Allanson J, Hutchinson PJ. Traumatic brain injury in adults. Pract Neurol. 2013;13(4):228-35.

13. Varma AK, Das A, Wallace G, Barry J, Vertegel AA, Ray SK, et al. Spinal cord injury: a review of current therapy, future treatments, and basic science frontiers. Neurochem Res. 2013;38(5):895-905.

14. Huang YH, Lee TC, Lee TH, Liao CC, Sheehan J, Kwan AL. Thirty-day mortality in traumatically brain-injured patients undergoing decompressive craniectomy. J Neurosurg. 2013; 118(6):1329-35 